\title{
Activation of Metabotropic Glutamate Receptors Induces Periodic Burst Firing and Concomitant Cytosolic $\mathrm{Ca}^{2+}$ Oscillations in Cerebellar Interneurons
}

\author{
Thibault Collin, ${ }^{1,2}$ Romain Franconville, ${ }^{1}$ Barbara E. Ehrlich, ${ }^{3}$ and Isabel Llano ${ }^{1}$ \\ ${ }^{1}$ Centre National de la Recherche Scientifique, Laboratoire de Physiologie Cérébrale, Université Paris Descartes, Paris 75006, France, ${ }^{2}$ Université Paris \\ Diderot, Paris 75013, France, and ${ }^{3}$ Department of Pharmacology and Cellular and Molecular Physiology, Yale University, New Haven, Connecticut 06520
}

Little is known about the generation of slow rhythms in brain neuronal circuits. Nevertheless, a few studies, both from reconstituted systems and from hippocampal slices, indicate that activation of metabotropic glutamate receptors (mGluRs) could generate such rhythms. Here we show in rat cerebellar slices that after either release of glutamate by repetitive stimulation, or direct stimulation of type 1 mGluRs, molecular layer interneurons exhibit repetitive slow $\mathrm{Ca}^{2+}$ transients. By combining cell-attached patch-clamp recording with $\mathrm{Ca}^{2+}$ imaging, we show that the regular $\mathrm{Ca}^{2+}$ transients (mean frequency, $35 \mathrm{mHz}$ induced by $2 \mu \mathrm{m}$ quisqualate in the presence of ionotropic glutamate receptor blockers) are locked with bursts of action potentials. Nevertheless, the $\mathrm{Ca}^{2+}$ transients are not blocked by tetrodotoxin, indicating that firing is not necessary to entrain oscillations. The first $\mathrm{Ca}^{2+}$ transient within a train is different in several ways from subsequent transients. It is broader than the subsequent transients, displays a different phase relationship to associated spike bursts, and exhibits a distinct sensitivity to ionic and pharmacological manipulations. Whereas the first transient appears to involve entry of $\mathrm{Ca}^{2+}$ ions through transient receptor potential channel-like channels and secondarily activated L-type Ca ${ }^{2+}$ channels, subsequent transients rely mostly on an exchange of $\mathrm{Ca}^{2+}$ ions between the cytosol and D-myo-inositol-1,4,5-triphosphate-sensitive intracellular $\mathrm{Ca}^{2+}$ stores. The slow, highly regular oscillations observed in the present work are likely to drive pauses in postsynaptic Purkinje cells, and could play a role in coordinating slow oscillations involving the cerebello-olivar circuit loop.

\section{Introduction}

Interneuron networks in the hippocampus and cortex are able to generate rhythms with frequencies ranging from a few tens of Hertz to a few hundreds of Hertz, which are believed to play a key role in information processing in these brain areas (McBain and Fisahn, 2001). The conditions under which these networks can generate rhythms in a slower time domain remain unclear. In heterologous systems, it has been shown that activation of group I metabotropic glutamate receptors (mGluRs) (mGluR1 and mGluR5) can lead to regular $\mathrm{Ca}^{2+}$ signals with a period on the order of tens of seconds (Kawabata et al., 1996, 1998). These signals depend on the recruitment of intracellular $\mathrm{Ca}^{2+}$ stores. In certain hippocampal interneurons, mGluR activation leads to an oscillatory inward current response (McBain et al., 1994) which correlates with periodic $\mathrm{Ca}^{2+}$ waves and action potential bursts (Woodhall et al., 1999). Thus, activation of mGluRs located on hippocampal interneurons is able to generate slow neuronal rhythms. However, much remains to be known concerning the

Received April 20, 2009; revised June 12, 2009; accepted June 17, 2009.

This work was supported by the Centre National de la Recherche Scientifique, by a grant from the Agence Nationale de la Recherche, and by a fellowship from the Fondation pour la Recherche Médicale to R.F. We thank Dr. Alain Marty for valuable discussions and for his comments on this manuscript.

Correspondence should be addressed to Isabel Llano, Laboratoire de Physiologie Cérébrale, Université Paris Descartes, 45 rue des Saints Pères, Paris 75006, France. E-mail: isabel.Ilano@parisdescartes.fr.

D0I:10.1523/JNEUROSCI.1865-09.2009

Copyright $\odot 2009$ Society for Neuroscience $\quad$ 0270-6474/09/299281-11\$15.00/0 sources, underlying cellular mechanisms, and functional consequences of such rhythms.

In the cerebellar cortex, Karakossian and Otis (2004) reported that stimulation of parallel fibers (PFs) under conditions in which ionotropic glutamate receptors are inhibited, or application of a specific agonist of mGluR1 generate a synaptic current in molecular layer interneurons (MLIs). These authors also showed that activation of group I mGluRs leads to increased MLI spiking and subsequent enhancement of the frequency of spontaneous synaptic currents recorded from Purkinje cells (PCs), in accord with previous data obtained using a broad spectrum agonist (Llano and Marty, 1995). Interestingly, mGluR1 has been identified in MLIs at postsynaptic locations by immunogold staining (Baude et al., 1993). These data prompted us to search for the presence of periodic changes in MLI behavior linked to mGluR activation and to dissect the cellular mechanisms underlying these changes. Here we report that glutamate release resulting from stimulation of glutamatergic fibers produces $\mathrm{Ca}^{2+}$ transients in MLI somata, through activation of mGluR1. Long-lasting activation of these receptors leads to robust $\mathrm{Ca}^{2+}$ oscillations that last for the entire duration of agonist application. Each $\mathrm{Ca}^{2+}$ transient is accompanied by a burst of action potentials, which correlates with the onset of the transient. A pharmacological study of the signal suggests that phospholipase C-mediated production of D-myo-inositol-1,4,5-triphosphate $\left(\operatorname{Ins}_{3}\right)$ is not necessary to produce the first $\mathrm{Ca}^{2+}$ transient but is critical for maintaining the subsequent $\mathrm{Ca}^{2+}$ transients during prolonged administration of 
the agonist. Together, our results show that sustained mGluR1 activation leads to a dramatic switch in MLI spike pattern, from a slow tonic mode to a rapid burst mode, and that these changes in electrical activity correlate with $\mathrm{Ca}^{2+}$ oscillations.

\section{Materials and Methods}

Recording conditions. Cerebellar slices (200 $\mu \mathrm{m}$ thick) were prepared from rats aged 13-17 d, decapitated after cervical dislocation in accordance with the animal care and use guidelines of the host institution. Slices were cut using a Leica VT1200S vibratome, from tissue submerged in ice-cold bicarbonate-buffered saline (BBS) containing (in $\mathrm{mM}$ ): 125 $\mathrm{NaCl}, 2.5 \mathrm{KCl}, 1.25 \mathrm{NaH}_{2} \mathrm{PO}_{4}, 26 \mathrm{NaHCO}_{3}, 2 \mathrm{CaCl}_{2}, 1 \mathrm{MgCl}_{2}$, and 10 glucose, bubbled with carbogen $\left(95 \% \mathrm{O}_{2}, 5 \% \mathrm{CO}_{2}\right)$. Sagittal slices were used in all experiments except those dealing with synaptic activation of mGluRs, for which coronal slices were preferred because parallel fibers are better preserved. The slices were maintained in carbogen-bubbled $\mathrm{BBS}$ at $35^{\circ} \mathrm{C}$ for $1 \mathrm{~h}$ before transfer to the recording setup. During experiments, the slices were perfused $(1.5 \mathrm{ml} / \mathrm{min})$ with BBS. Experiments were performed at room temperature $\left(20-24^{\circ} \mathrm{C}\right)$ unless otherwise indicated.

$\mathrm{Ca}^{2+}$ imaging and electrophysiology. Either wide-field imaging or twophoton laser scanning microscopy (2PLSM) was used, as detailed in previous publications (Collin et al., 2005 and references therein). In most experiments, images were formed at dwell times of 100-500 ms. Electrical recordings were based on an EPC-10 patch-clamp amplifier (HEKA Electronik) synchronized with the digital imaging system or the 2PLSM system by a TTL trigger. In a subset of experiments designed to assess the temporal relation between spike bursts and $\mathrm{Ca}^{2+}$ rises, the standard scanning routines used in the homemade 2PLSM setup (Tan et al., 1999) were replaced by a procedure which maintains the laser beam at the center of the MLI soma throughout the recording. In this "laser pointing" protocol, photodetector signals were acquired at $100 \mu \mathrm{s} /$ point in parallel with electrical signals from the patch-clamp amplifier (see Fig. 2 B). Fluorescence signals were analyzed in terms of the changes in fluorescence relative to prestimulus values ( $\Delta F / F_{\mathrm{o}}$, expressed as percentage) with software written in the IGOR-Pro programming environment (Wavemetric). When illustrating examples of images constructed from 2PLSM experiments, the pseudocolor bar codes for fluorescence in Hertz, which is calculated from the number of photons acquired with an avalanche photodiode during $10 \mu$ s sampling intervals.

Most of the experiments used the preloaded condition, described previously for MLIs (Conti et al., 2004). Briefly, whole cell recordings (WCRs) were established in MLIs with pipette solutions containing (in mM): $140 \mathrm{~K}$-gluconate, $5.4 \mathrm{KCl}, 4.1 \mathrm{MgCl}_{2}$, 9.9 HEPES-K, 0.36 Na-GTP, and 3.6 Na-ATP and $100 \mu \mathrm{M}$ the $\mathrm{Ca}^{2+}$-sensitive indicator Oregon Green 488 BAPTA-1 (OG1) (Invitrogen). Pipette input resistances were in the $8-10 \mathrm{M} \Omega$ range. MLI identification was confirmed by the observation of large $(0.8-1.7 \mathrm{nA})$, transient inward currents when the membrane potential was stepped for $-70 \mathrm{mV}$ to $-10 \mathrm{mV}$ for $2 \mathrm{~ms}$ (Collin et al., 2005). The pipette solution was allowed to equilibrate with the cytosol for $30-45 \mathrm{~s}$ and the pipette was then removed. If a high-resistance ( $>1 \mathrm{G} \Omega$ ) outside-out membrane patch was obtained, the preloaded MLI was considered suitable for $\mathrm{Ca}^{2+}$ imaging.

For simultaneous recordings of $\mathrm{Ca}^{2+}$ transients and spike activity, a new patch pipette was approached to a preloaded MLI. A high resistance seal was established and currents were monitored, maintaining the pipette potential at $0 \mathrm{mV}$. Analysis of the electrical signals for spike detection was conducted in IGOR-Pro (Wavemetric).

Experiments on mGluR-evoked currents in conjunction with $\mathrm{Ca}^{2+}$ transients were done in the WCR configuration, with the same pipette solution as that used for preloading experiments. For the recording of the current-voltage relation of the mGluR-activated current, a $\mathrm{K}^{+}$-free solution was used to eliminate the contribution of voltage-gated $\mathrm{K}^{+}$channels. This solution contained, in mM: 140 Cs methanesulfonate, 10 BAPTA-Cs, 10 HEPES-Cs, $2 \mathrm{MgCl}_{2}, 5 \mathrm{CaCl}_{2}, 0.4 \mathrm{Na}$-GTP, and $4 \mathrm{Na}$-ATP.

Unless otherwise stated, BBS contained blockers of ionotropic $\mathrm{GABA}_{\mathrm{A}}$ (20 $\mu \mathrm{M}$ bicuculline methochloride) and glutamate receptors: $20 \mu \mathrm{M} \mathrm{2,3-}$ dioxo-6-nitro-1,2,3,4-tetrahydrobenzo[f]quinoxaline-7-sulfonamide (NBQX) and $100 \mu \mathrm{M} \mathrm{D}-(-)$-2-amino-5-phosphonopentanoic acid (D-APV). The high concentration of NBQX used ensured that the block was effective during sustained agonist application. These compounds, as well as 1-aminoindan-1,5-dicarboxylic acid (AIDA), L-quisqualic acid (Quis), (S)-3,5-dihydroxyphenylglycine (DHPG), and 7(hydroxyimino)cyclopropa $[b]$ chromen-1a-carboxylate ethyl ester (CPCCOEt), were purchased from Tocris Bioscience. Ryanodine was purchased from Ascent Scientific. All other chemicals were purchased from Sigma/Calbiochem. Stocks of ryanodine, CPCCOEt, U73122, 2 -amino phenyl borate (2-APB), and nimodipine were prepared in DMSO at concentrations of $100,100,2,90$, and $100 \mathrm{~mm}$, respectively. All other stocks were prepared in $\mathrm{H}_{2} \mathrm{O}$. For experiments in which extracellular $\mathrm{Ca}^{2+}$ was removed, $100 \mu \mathrm{M}$ EGTA was added to a $\mathrm{Ca}^{2+}$-free BBS.

Extracellular stimulation of glutamatergic inputs was performed in coronal slices by applying trains of voltage pulses (100 $\mu$ s duration; $40-60 \mathrm{~V}$ amplitude) between a reference platinum electrode and another platinum electrode carried by a $2-\mu \mathrm{m}$-tip-diameter glass pipette filled with a HEPES-buffered solution (HBS) containing (in $\mathrm{mM}$ ): $145 \mathrm{NaCl}$, $2.5 \mathrm{KCl}, 2 \mathrm{CaCl}_{2}, 1 \mathrm{MgCl}_{2}, 10$ HEPES-Na; input resistance of $2-3 \mathrm{M} \Omega$. This pipette was repositioned in the molecular layer until a stable $\mathrm{Ca}^{2+}$ rise response was evoked. Stimulus trains at frequencies of $25-50 \mathrm{~Hz}$ gave responses with peak $\Delta F / F_{\mathrm{o}}$ amplitude and duration which did not differ significantly. Results have been pooled together. In preliminary experiments, we verified using WCRs that this type of electrical stimulation elicited synaptic currents consistent with those described previously for PF-MLI synapses (Carter and Regehr, 2000; Rossi et al., 2008).

To study agonist-evoked responses, puffs (1 s duration) of group I mGluR agonists were applied with a puffer pipette ( $2 \mu \mathrm{m}$ tip opening, located 20-30 $\mu \mathrm{m}$ from the MLI soma) connected to a Picospritzer (General Valve) set at 5-7 psi. The pipette was filled with HBS plus either $2 \mu \mathrm{M}$ Quis, $20 \mu \mathrm{M}$ NBQX, and $100 \mu \mathrm{M}$ D-APV, or $50 \mu \mathrm{M}$ DHPG.

Statistical values are given as mean \pm SEM; $n$ refers to the number of cells. Unless otherwise noted, the paired Student's $t$ test was used to evaluate statistical differences. Results were considered significantly different if $p \leq 0.05$.

\section{Results}

\section{Repetitive stimulation of glutamatergic fibers induces an mGluR1-mediated $\mathrm{Ca}^{2+}$ increase in MLIs}

In the cerebellar cortex, PFs form tightly knit bundles of axons that fill a large fraction of the space of the molecular layer. Consequently, concerted stimulation of a bundle of PFs results in a homogeneous elevated glutamate concentration in the molecular layer that decreases relatively slowly because of the inefficiency of removal by diffusion (Barbour and Häusser, 1997). This elevated glutamate generated by repetitive stimulation of PFs has been shown to stimulate various ionotropic receptors in MLIs (Carter and Regehr, 2000; Rossi et al., 2008). Repetitive PF stimulation also can induce an inward current in these neurons, with a pharmacological profile consistent with the activation of mGluR1 (Karakossian and Otis, 2004). Whether such activation can lead to changes in intracellular $\mathrm{Ca}^{2+}$ in MLIs, however, has not been investigated despite the importance of $\mathrm{Ca}^{2+}$ homeostasis in multiple aspects of neuronal function.

To investigate the relationship between activation of mGluRs and $\mathrm{Ca}^{2+}$ signals, we first preloaded individual MLIs with the $\mathrm{Ca}^{2+}$ sensitive indicator OG1 using a short WCR (preloaded MLI; Conti et al., 2004; Rengifo et al., 2007) (see Materials and Methods), and then followed the fluorescence signals in response to stimulation of glutamatergic fibers. As shown in Figure 1, A1 and $A 2$, a $40 \mathrm{~Hz}$ train of stimuli, in the presence of the ionotropic receptor blockers NBQX, D-APV, and bicuculline, led to an increase in somatic fluorescence, with peak $\Delta F / F_{\mathrm{o}}$ values of $108.5 \pm$ $8.9 \%$ (average of 10 experiments with stimuli trains of 1-2 min duration). When cells were repetitively stimulated over a period of $>40 \mathrm{~min}$, the magnitude of the response was maintained (Fig. 

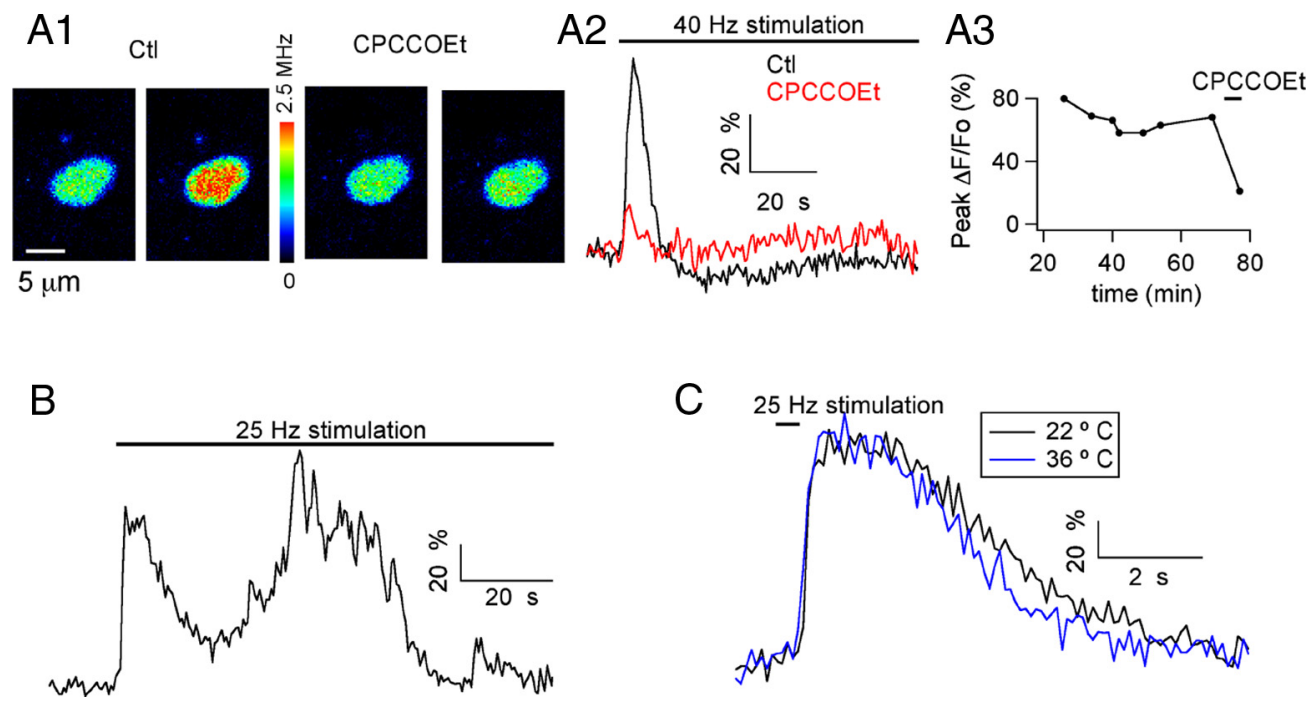

Figure 1. Stimulation of glutamatergic fibers induces mGluR1-dependent $\mathrm{Ca}^{2+}$ rises in MLI somata. A1, Pseudocolor images from a MLI soma preloaded with the $\mathrm{Ca}^{2+}$-dependent indicator $0 \mathrm{G1}$ taken at rest and at the peak of the response to a 1.5-min-long train of stimuli at $40 \mathrm{~Hz}$. Images are shown in control solution (first and second images) and in the presence of a $100 \mu \mathrm{m} \mathrm{concentration}$ of the mGluR1 antagonist (PCCOEt (third and fourth images). A2, Time course for the $\Delta F / F_{0}$ signals. A3, Evolution of the peak $\Delta F / F_{0}$ values as a function of time in WCR before and during exposure to $\mathrm{CPCCOEt}$. Experiment conducted at $22^{\circ} \mathrm{C} . \boldsymbol{B}$, In another preloaded $\mathrm{MLI}$ soma, extracellular stimulation ( $25 \mathrm{~Hz}, 1.6$ min duration) evoked oscillatory changes in $\mathrm{Ca}^{2+}$. Experiment $\mathrm{Conducted} \mathrm{at} 36^{\circ} \mathrm{C}$. C, Time course of the somatic $\mathrm{Ca}^{2+}$ signals elicited in another MLI by a $0.4 \mathrm{~s}$ train of $25 \mathrm{~Hz}$ stimuli at $22^{\circ} \mathrm{C}$ and $36^{\circ} \mathrm{C}$. In this and subsequent figures, the pseudocolor bar for images from $2 \mathrm{PLSM}$ is expressed in $\mathrm{Hz}$, calculated from the number of photons acquired during $10 \mu$ s sampling intervals. Note that in all experiments, ionotropic GABA and glutamate receptors were blocked by a mixture of antagonists, as specified in Materials and Methods.

1A3). The response was strongly inhibited or, in several cases, totally abolished by application of the selective mGluR1 antagonist CPCCOEt $(100 \mu \mathrm{M})$ (Fig. 1 A1, A2). On average, the response decreased to $26.6 \pm 8.9 \%$ of the control value in six cells $(p<$ 0.0002 ), and after washout of the antagonist, the response recovered to $48.7 \pm 16.0 \%$ of the control value $(n=3)$. In view of recent reports on actions of CPCCOEt unrelated to mGluRs (Fukunaga et al., 2007; Shin et al., 2009), we tested AIDA, a selective mGluRla antagonist that is not structurally related to CPCCOEt (Moroni et al., 1997; Otani et al., 1999). Fluorescence signals elicited by trains of extracellular stimulation were decreased to $50 \%$ of their control value after $8-11$ min of exposure to this drug $(n=4 ; p<0.003)$. The smaller degree of block of AIDA compared with CPCCOEt is attributable to the competitive nature of this blocker (Moroni et al., 1997).

The fluorescence signals displayed a first transient that lasted, on average, $37.6 \pm 8.1 \mathrm{~s}(n=10)$, and were followed by later transients in 5 of 10 recordings (Fig. $1 B$, see example). Although $\mathrm{Ca}^{2+}$ responses having a single peak could be elicited by short trains of extracellular stimulation (Fig. 1C, see example), the later transients were obtained only if the electrical stimulation was maintained, suggesting that agonist binding by mGluRs is a prerequisite for the generation of repetitive $\mathrm{Ca}^{2+}$ rises. Another feature of the responses to electrical stimulation was their weak temperature sensitivity. That is, the first transient was similar in amplitude and time course at $22^{\circ} \mathrm{C}$ and at physiological temperature (Fig. $1 C$, see example). The ratio of peak $\Delta F / F_{\mathrm{o}}$ values at $36^{\circ} \mathrm{C}$ over values at $22^{\circ} \mathrm{C}$ was $0.94 \pm 0.10$, and the corresponding ratio for the duration of the first transient was $0.95 \pm 0.21(n=4)$. In summary, our results show that after glutamate release resulting from stimulation of glutamatergic fibers, MLI somata produce $\mathrm{Ca}^{2+}$ transients in response to activation of mGluR1 and that this process does not have a strong temperature sensitivity.

\section{Rhythmic $\mathrm{Ca}^{2+}$ signals in response to $\mathrm{mGluR}$ activation}

To study more directly the $\mathrm{Ca}^{2+}$ signals elicited by stimulation of glutamatergic fibers, we then directly applied the potent agonist of group I mGluRs, quisqualate $(2 \mu \mathrm{M})$, in the presence of ionotropic blockers. Addition of quisqualate elicited a series of $\mathrm{Ca}^{2+}$ transients which, as illustrated in Figure $2 \mathrm{~A}$, lasted for the entire duration of agonist application (up to $10 \mathrm{~min}$ ) and stopped after the agonist was removed from the bath. In preloaded MLIs, mGluR-induced $\mathrm{Ca}^{2+}$ responses had an average frequency of $35.2 \pm 2.3 \mathrm{mHz}(n=82)$ and were quite robust, with only $13 \%$ of the cells failing to show the oscillatory $\mathrm{Ca}^{2+}$ signals. These $\mathrm{Ca}^{2+}$ signals had similar features whether they were recorded from MLIs with somata located within $20 \mu \mathrm{m}$ of the Purkinje cell layer, presumably basket cells, or from MLIs with somata located in the middle and upper molecular layer, presumably stellate cells. Thus, average values for the peak amplitude and oscillation frequency were $106 \pm 4.8 \%$ and $33.5 \pm 2.3 \mathrm{mHz}$ for stellate cells $(n=71)$, whereas values for basket cells were $92 \pm 10.5 \%$ and $46.2 \pm 8.2 \mathrm{mHz}(n=11) ; p>0.24$ for peak amplitude and $p>$ 0.16 for oscillation frequency (nonpaired Student's $t$ test).

For a given MLI, there was little variation in the peak amplitude of the transients throughout the response (Fig. $2 \mathrm{~A}$ ). Furthermore, the frequency of the transients was also remarkably constant throughout the response, as documented below. Finally, there was little variation when comparing responses to separate agonist application in a given cell.

\section{First versus subsequent $\mathrm{Ca}^{2+}$ transients}

We found that the first transient is consistently broader than the subsequent transients, whereas all subsequent transients are remarkably similar in shape (Fig. 2; further examples may be seen in Figs. 3 and 4 and, below, in Fig. 8). This difference in duration between the first and subsequent transients translated into a highly significant difference for their areas $\left(\% \Delta F / F_{\mathrm{o}} \cdot \mathrm{s}\right.$ values were $1918 \pm 171$ and $648 \pm 87$ for the first and the secondary 
areas, respectively; ratio of the average of the secondary area to the first area, for the same cells: $0.34 \pm 0.03, n=23 ; p<0.0002$ for paired Student's $t$ test). The mean value for the areas under the first agonistinduced $\mathrm{Ca}^{2+}$ transient is not statistically different from that of the $\mathrm{Ca}^{2+}$ response to extracellular stimulation $(2602 \pm 655 \% \Delta F /$ $F_{\mathrm{o}} \cdot s ; n=10 ; p>0.34$, nonpaired Student's $t$ test). The peak amplitude of the first transient for the same cells $(110.3 \pm 9.1 \%, n=$ 23 ) is also comparable to that elicited by extracellular stimulation [average peak value of $108.5 \%$ in 10 experiments (see Repetitive stimulation of glutamatergic fibers induces an mGluR1-mediated $\mathrm{Ca}^{2+}$ increase in MLIs); $p>0.24$, nonpaired Student's $t$ test]. Thus, the two responses share similar magnitudes and temporal course.

Once the first transient was past, areas under $\mathrm{Ca}^{2+}$ transients calculated for subsequent transients displayed a remarkably small coefficient of variation (0.159 \pm $0.017 ; n=23$ ), indicating a high degree of reproducibility for these transients. These results suggest that there are two different types of $\mathrm{Ca}^{2+}$ transients generated by quisqualate application, and that a distinction must be made between the first transient and all subsequent transients. Note, however, that the late transients elicited by prolonged extracellular stimulation (as in Fig. 1) were less regular and reproducible than those elicited by quisqualate. Finding the reason for this difference would presumably require further investigation of the specific effects of various extracellular stimulation parameters on the late calcium fluctuations.

\section{Relation between $\mathrm{Ca}^{2+}$ transients and spike firing}

To correlate the electrical activity of the cell with the $\mathrm{Ca}^{2+}$ signals, we performed experiments in which the preloaded MLI was subjected to a cell-attached patchclamp recording in parallel to $\mathrm{Ca}^{2+}$ imaging (Fig. 2A). Under these conditions, the spontaneous firing rate of MLIs was $0.83 \pm 0.42 \mathrm{~Hz}(n=6)$. This value is lower than that published by Häusser and Clark (1997) from recordings from older rats (postnatal day 18-32) or by MannMetzer and Yarom (1999) for work in adult guinea pigs, both of which obtain average firing rates around $12 \mathrm{~Hz}$. For juvenile MLIs, spontaneous spike rates were reported for the presynaptic partner of MLI-MLI pair recordings (Kondo and Marty, 1998, their Table 1). Their higher average value $(3.2 \mathrm{~Hz})$ compared with ours is likely to arise from the fact that in
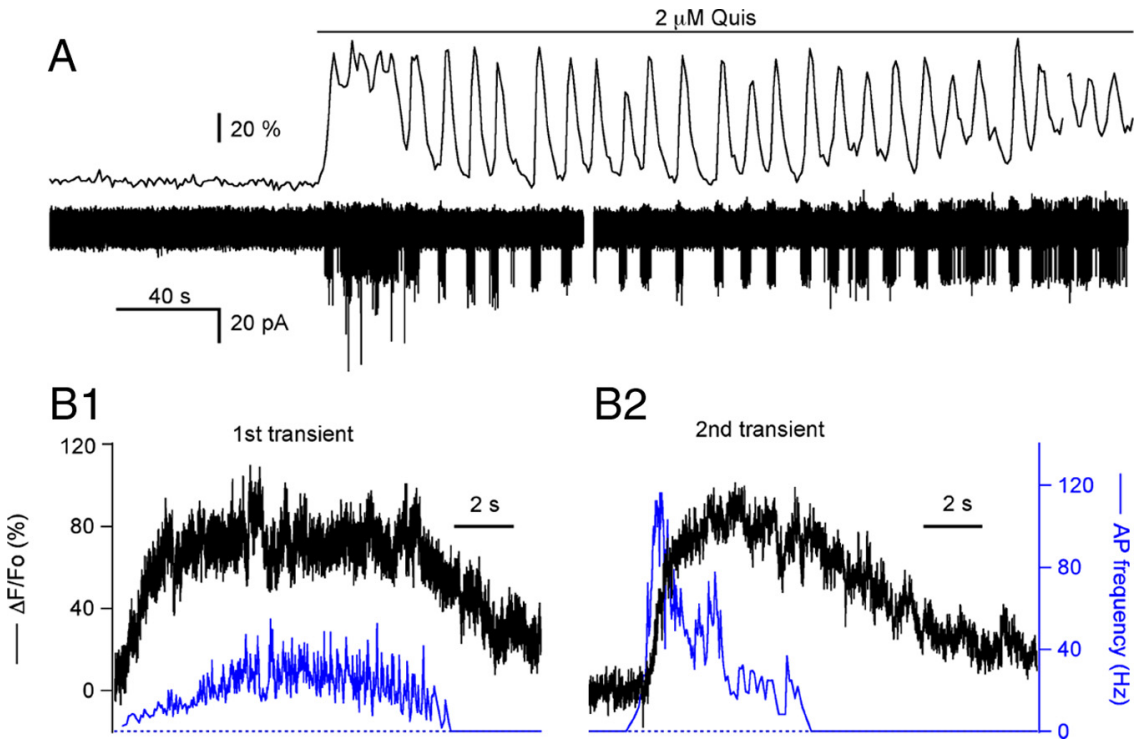

Figure 2. Synchronized oscillations in MLI spiking and $\mathrm{Ca}^{2+}$ rises induced by mGluR1 activation. $\boldsymbol{A}, \Delta F / F_{0}$ signals from the soma of a preloaded MLI (top trace) were acquired in parallel with the membrane currents recorded by a patch pipette in the cell-attached configuration (bottom trace). This MLI showed no spiking activity at rest; bath application of $2 \mu \mathrm{M}$ quisqualate induced spike bursts and oscillatory changes in $\mathrm{Ca}^{2+}$. The gap in the current record corresponds to a short pause in the acquisition of the electrophysiological signal. $\boldsymbol{B}$, Analysis of the $\Delta F / F_{0}$ signals and of the instantaneous action potential frequency from another MLI during the first $(\boldsymbol{B} 1)$ and second $(\boldsymbol{B} 2)$ transients of an oscillatory response to bath applied quisqualate. Note that the first transient exhibits less adaptation for both, the $\mathrm{Ca}^{2+}$ transient and the spike frequency increase.
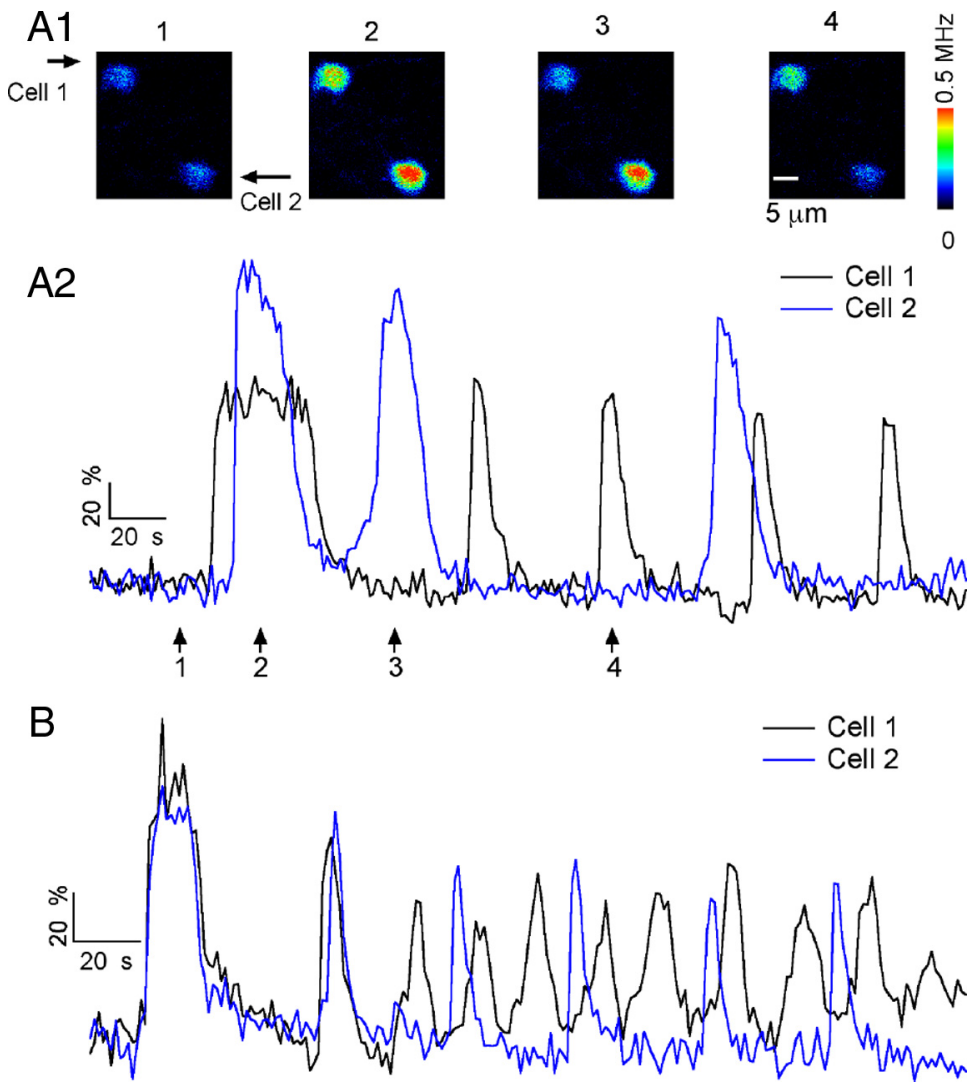

Figure 3. Oscillations recorded from pairs of adjacent MLIs. A1, Pseudocolor images from a pair of preloaded MLIs at rest (1) and at succeeding times during exposure to $2 \mu \mathrm{m}$ quisqualate (2-4). $A 2$, Time course of $\Delta F / F_{0}$ signals for the $2 \mathrm{MLIs}$ that oscillate out of synchrony. The arrows indicate the time for the images shown in $A 1$. $B$ shows the $\Delta F / F_{0}$ time course from a different pair of MLIs. In this case, the fluorescent transients show evidence of synchronization. 

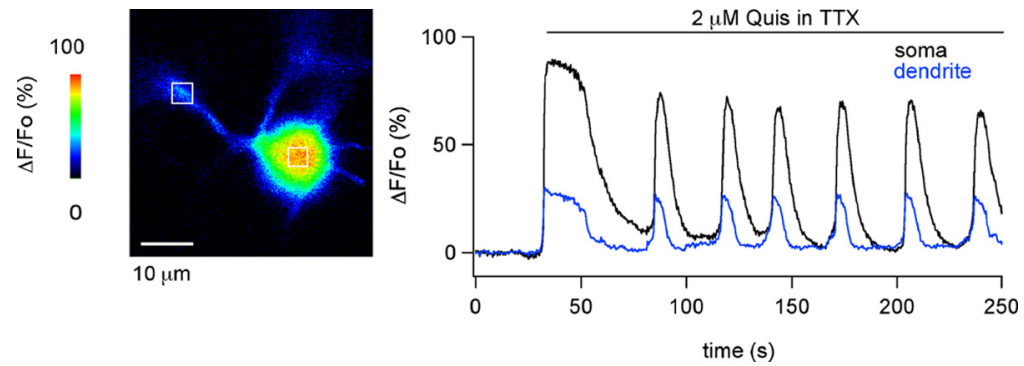

Figure 4. Action potentials are not required for the generation of mGluR1-induced $\mathrm{Ca}^{2+}$ oscillations. Left, $\Delta F / F_{0}$ image of a portion of the somatodendritic compartment of a preloaded MLI at the peak of the response to bath-applied quisqualate $(2 \mu \mathrm{M})$ in TTX containing BBS. Right, Time course of the $\Delta F / F_{0}$ signals measured in a region of interest (ROI) over the soma center (black trace) and another ROI on the proximal dendrite (blue trace).

their work, silent MLIs would have been discarded, because the aim was to obtain a synaptically connected pair.

The experiments revealed that each $\mathrm{Ca}^{2+}$ transient was accompanied by a burst of action potentials. We analyzed the electrical activity in terms of the burst duration and the instantaneous spike frequency. As with the $\mathrm{Ca}^{2+}$ response, the first burst of action potentials was distinct from the following bursts. In six cells, the duration of the first spike burst was $15.9 \pm 3.9 \mathrm{~s}$, whereas the second burst lasted $4.6 \pm 0.7 \mathrm{~s}$. The ratio between spike durations for the first versus subsequent bursts $(0.32 \pm 0.13)$ corresponds to the ratio between the areas of the respective $\mathrm{Ca}^{2+}$ transients in the same recordings $(0.39 \pm 0.11)$. The temporal pattern of firing within a burst also depended on the burst number. This is illustrated in Figure $2 B$, from an experiment in which laser pointing was used to attain a fast sampling of the fluorescence signals (see Materials and Methods). To compare the first (Fig. 2B1) and the second (Fig. 2B2) transient, they have been illustrated in terms of the changes in fluorescence (black traces) and the time-locked action potential frequency (blue traces). Note that, although the peak of firing frequency occurred at the peak of the $\mathrm{Ca}^{2+}$ response for the first wave, maximum spiking frequency is reached at the onset of the $\mathrm{Ca}^{2+}$ response for the subsequent transients. The spike frequency reached higher levels during the second burst $(70.1 \pm 6.1 \mathrm{~Hz}$, averaged for 6 cells) than during the first burst $(30.8 \pm 4.0 \mathrm{~Hz}$, averaged for the same 6 cells). The ability to maintain a high spike frequency during the burst also differed when comparing the first and subsequent bursts. A measure of the spike frequency sag over the duration of the burst is the ratio of the spike frequency at the end of the burst divided by the peak spike frequency. This parameter, the spike frequency sag, shows that the second burst decayed to a greater extent than the first burst (the spike frequency sag was $0.61 \pm$ 0.09 for the first burst and $0.27 \pm 0.06$ for the second burst; $n=$ 6) despite the longer duration of the first burst.

Neighboring MLIs have been shown to couple via gap junctions in the adult guinea pig cerebellum (Mann-Metzer and Yarom, 1999). The influence of gap junctions on cell synchrony is heavily frequency dependent. Thus, although gap junctions are too weak in juvenile rats to induce a marked coupling between individual spikes (Vincent and Marty, 1996), it seemed plausible that it would be sufficient to synchronize quisqualate-induced bursts among neighboring MLIs. Therefore, we investigated the possibility that electrical coupling contributes to the oscillatory behavior induced by mGluR activation, by simultaneously recording the $\mathrm{Ca}^{2+}$ signals in pairs of preloaded MLIs whose somas were placed within $50 \mu \mathrm{m}$ of each other. In 5 of 10 simultaneous recordings, as illustrated in Figure $3 A$, the cells were totally out of synchrony. In the other five recordings, evidence of synchronization was obtained, but the waves were not entirely in phase. An example of such a hybrid case is displayed in Figure $3 B$. In this case, the two first waves coincide in time for the two recorded cells; later, the waves occur out of synchrony, but one of the cells (black trace) adopts a frequency that is exactly twice that of the other cell (blue trace), and during each blue cycle, the two peaks of the black trace occur with a fixed phase delay with regard to the blue trace. Such behavior is unlikely to occur by chance and suggests that on quisqualate application, the gap junctions in the MLI network induce, first, synchrony and, later, a phase-locked harmonic coupling between the two recorded cells. Together, the results show that in the present preparation, there is either no coupling or incomplete coupling between quisqualate-induced bursts in adjacent neurons. However, it should be kept in mind that, for reasons that are still unclear, the degree of electrical coupling is weak in slices from juvenile rats, and it can be surmised that in conditions in which the coupling is stronger (e.g., adult guinea pigs) (Mann-Metzer and Yarom, 1999), synchrony may be much more extensive than that illustrated in Figure 3.

Given the concerted changes in spike pattern and $\mathrm{Ca}^{2+}$ signaling, the question arises as to whether depolarization-induced $\mathrm{Ca}^{2+}$ influx is sufficient to explain the $\mathrm{Ca}^{2+}$ transients. To address this issue, quisqualate responses were analyzed in neurons bathed in TTX to eliminate action potentials. Under these conditions, robust $\mathrm{Ca}^{2+}$ oscillations were obtained (Fig. 4) with amplitude and frequency parameters comparable to those obtained in the absence of TTX (control peak amplitude and frequency: $105.7 \pm 5.1 \%$ and $30.6 \pm 2.6 \mathrm{mHz}, n=66$; respective values in TTX: $149.4 \pm 13.4 \%$ and $21.4 \pm 2.4 \mathrm{mHz}, n=8$ ). Similar results were obtained when the $\mathrm{Ca}^{2+}$ responses to the specific group I mGluR agonist DHPG were studied. Thus, the peak amplitude and frequency of responses to this agonist in the absence of TTX were $96.2 \pm 25.3 \%$ and $33.3 \pm 14.8 \mathrm{mHz}(n=4)$, and the corresponding values in TTX were $104.3 \pm 28.0 \%$ and $27.8 \pm 5.5 \mathrm{mHz}$ $(n=3)$.

In MLIs, sustained application of $\mathrm{GABA}_{\mathrm{A}} \mathrm{R}$ agonists has been previously shown to elicit $\mathrm{Ca}^{2+}$ signals that are caused by the accumulation of $\mathrm{Cl}^{-}$ions in the cytosol (Chavas et al., 2004). Because mGluR- and $\mathrm{GABA}_{\mathrm{A}} \mathrm{R}$-mediated signals are superficially similar, we compared several aspects of the two responses with the aim to discover whether they share a common cellular mechanism. We found that, whereas $\mathrm{GABA}_{\mathrm{A}} \mathrm{R}$-mediated $\mathrm{Ca}^{2+}$ signals are initiated in dendrites and then travel as $\mathrm{Ca}^{2+}$ waves toward the cell soma (Chavas et al., 2004), mGluR-mediated $\mathrm{Ca}^{2+}$ signals rose simultaneously in the soma and in dendrites (Fig. 4). Furthermore, contrary to $\mathrm{GABA}_{\mathrm{A}} \mathrm{R}$-mediated $\mathrm{Ca}^{2+}$ signals, which are larger in dendrites than in the soma (Chavas et al., 2004), the mGluR-mediated signals were either smaller in dendrites than in the soma (Fig. 4, see example) or had similar sizes in both compartments (Fig. 6, see example). On average, the ratios of peak dendritic signal to peak somatic signal were $0.66 \pm 0.25$ in TTX $(n=4)$ and $0.91 \pm 0.04$ in the absence of TTX $(n=6)$.

Together, these data show that sustained activation of group I mGluRs leads to a dramatic switch in MLI spike pattern, from a slow tonic mode to a rapid burst mode, and the changes in spik- 
ing pattern correlate with $\mathrm{Ca}^{2+}$ oscillations. However, the spikes are not necessary to sustain the $\mathrm{Ca}^{2+}$ oscillations.

\section{Ionic currents linked to activation of group I mGluRs}

The results described in the previous section were conducted in MLIs subjected to preloading, an experimental protocol which we developed to minimize alterations in the cell's intracellular environment (Conti et al., 2004; Chavas et al., 2004; Rengifo et al., 2007). Because previous reports (Karakossian and Otis, 2004) showed that mGluR1 activation in MLIs after either repetitive PF stimulation or direct agonist application elicits a cationic current, we next investigated the ionic counterpart of the mGluR responses. To our surprise, when MLIs were maintained in WCRs and challenged with puffs of agonists (either quisqualate or DHPG), $\mathrm{Ca}^{2+}$ transients were obtained in only 9 of 34 trials. This contrasted with results obtained with the preloading procedure in which puffs elicited a $\mathrm{Ca}^{2+}$ transient in all MLIs tested. There was a strict correlation between the existence of a $\mathrm{Ca}^{2+}$ rise and that of an ionic current. In all WCR cases in which inward currents were recorded at -70 $\mathrm{mV}, \mathrm{Ca}^{2+}$ responses were obtained in parallel. In most responding MLIs, the amplitude of both the current and the $\mathrm{Ca}^{2+}$ transients decreased rapidly during recording, reflecting washout of an unknown cell constituent. Washout occurred with a similar time course for the two responses so that, within a single experiment, the two responses were in synchrony.

To determine the relationship between the currents and the $\mathrm{Ca}^{2+}$ responses, we collected measurements in the first minutes of WCR. Both current and $\mathrm{Ca}^{2+}$ transients started with a delay of $\sim 1 \mathrm{~s}$ after a puff application of agonist, presumably reflecting the slow activation kinetics of the receptors, and the response decayed back to baseline within 4-8 s (Fig. 5A,B). The $\mathrm{Ca}^{2+}$ and current transients had similar temporal courses, with slower currents corresponding to slower $\mathrm{Ca}^{2+}$ transients. In the two examples shown, the time constants of decay for the DHPG-activated currents differ by a factor of 3 (Fig. $5 A, B$, lower traces); the same factor describes the difference in the time constant of decay of the $\mathrm{Ca}^{2+}$ transients (Fig. 5A, B, upper traces). Average values for the DHPG-induced currents at $-70 \mathrm{mV}$ were $18 \pm 5 \mathrm{pA}$, with corresponding peak $\Delta F / F_{\mathrm{o}}$ signals of $87 \pm 4.5 \%(n=4)$, and averaged values for quisqualate (at $2 \mu \mathrm{M}$ )-induced currents were $64 \pm 11 \mathrm{pA}$ with peak $\Delta F / F_{\mathrm{o}}$ values of $103 \pm 26 \%(n=5)$.

These data show that the metabotropic currents and the initial $\mathrm{Ca}^{2+}$ rise are tightly linked, which strongly suggests a causal relation. Canonical transient receptor potential channels (TRPCs), first demonstrated to be present in brain tissue and susceptible to be activated by $\mathrm{G}_{\mathrm{q}}$-coupled receptors by Strübing et al. (2001), are attractive candidates to underlie the measured currents because they have been shown to link to group I mGluRs in neuronal cells (Gee et al., 2003; Bengtson et al., 2004; Berg et al., 2007; Ene et al., 2007; Wang et al., 2007) and are present in the rodent cerebellar cortex (Huang et al., 2007; Hartmann et al., 2008). In the cerebellar cortex, mGluR1-TRPC coupling has been described for PCs (Kim et al., 2003; Hartmann et al., 2008) (for a recent review,
B

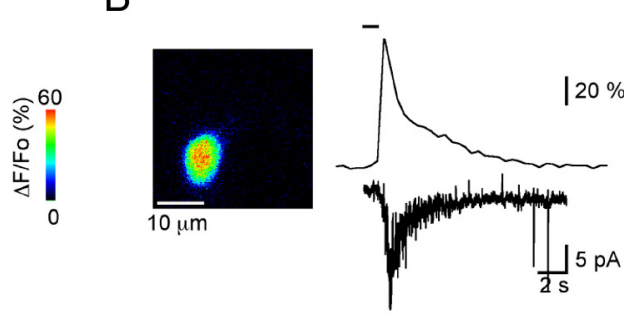

C2

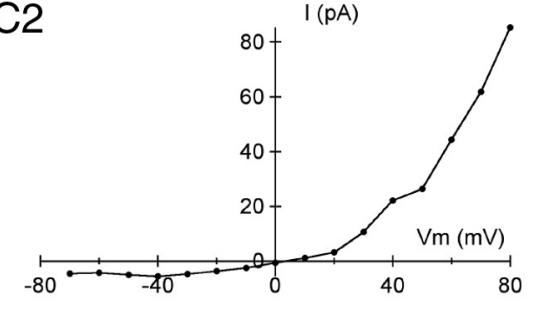

Fembrane currents induced by a group I mGluR agonist. $A$, Left, $\Delta F / F_{0}$ image of a portion of the somatodendritic 列 is methanesulfonate solutions are shown for two membrane potentials $(\mathbf{C} 1)$. Note the strong outward rectification, evident in the $\operatorname{MLI}(C 2)$.

see Hartmann and Konnerth, 2009). We therefore investigated whether the single-channel properties of the DHPG-activated current are compatible with a TRPC conductance. To obtain the value of the elementary current associated with the mGluRinduced responses, variance analysis of the DHPG-induced currents was performed on currents measured at early times in WCRs, in MLIs dialyzed with a Cs methanesulfonate solution, which minimizes the contribution of $\mathrm{K}^{+}$currents. In the six MLIs, this value was $1.25 \pm 0.24 \mathrm{pA}$ at $-70 \mathrm{mV}$. The corresponding single-channel conductance of $16 \mathrm{pS}$ compares to values for TRPC1 [16-20 pS; Vaca and Sampieri (2002)], TRPC3 [23 pS; Kamouchi et al. (1999)], and TRPC4 [18 pS; Walker et al. (2002)], when comparing values obtained from WCR measurements in cells bathed in saline containing $2 \mathrm{~mm}$ extracellular $\mathrm{Ca}^{2+}$. Generally, the single-channel conductance of other TRP channels is larger than the value obtained for TRPC1, 3, and 4.

To further characterize the mGluR-induced currents, we determined the current-voltage relationship using Cs methanesulfonateloaded MLIs, as done by Karakossian and Otis (2004) for the recording of mGluR-mediated EPSCs in these neurons. Under these conditions, the proportion of WCR trials in which mGluR agonist elicited an ionic current was also quite low. The reason for the strong washout of mGluR responses in the present experiments remains unknown. In 3 MLIs of 32 trials, the DHPGinduced currents were maintained long enough during the WCR to measure the voltage dependence of the current (Fig. 5C1, C2). We found a very strong outward rectification (Fig. 5C2), which is similar to that seen for TRPC3 channels (Kamouchi et al., 1999; Dietrich et al., 2003) but unlike the current-voltage relationship for TRPC1 and 4 (Pedersen et al., 2005; Owsianik et al., 2006; Ramsey et al., 2006; Clapham, 2009). The rectification found in the MLIs also differs from that seen in hippocampal CA3 pyramidal cells (Gee et al., 2003).

Together, our data suggest that TRPCs underlie the mGluRmediated currents in MLIs. 
A1 ctl

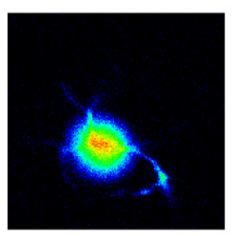

$1.5 \mathrm{~min}$. in $0 \mathrm{Ca}$

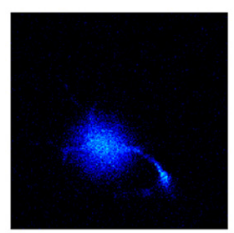

A2
$4.5 \mathrm{~min}$. in $\mathrm{O} \mathrm{Ca}$

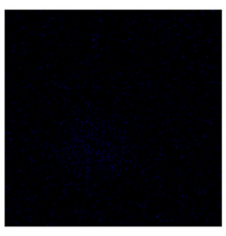

A3

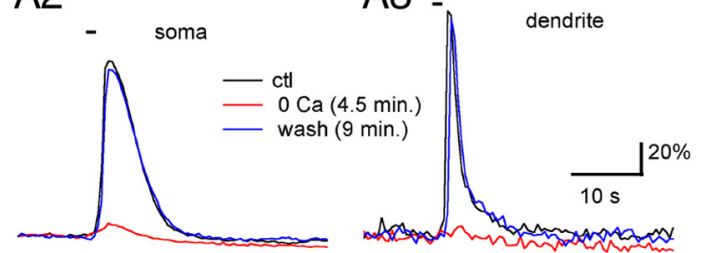

9 min. wash

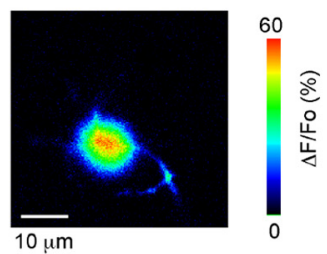

B

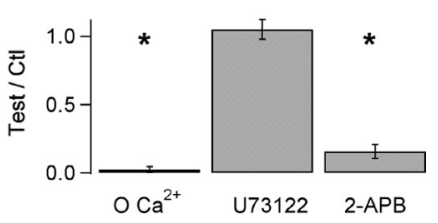

Figure 6. Pharmacological profile of the metabotropic $\mathrm{Ca}^{2+}$ transients. $A 1, \Delta F / F_{0}$ images corresponding to the peak of the $\mathrm{Ca}^{2+}$ response to a $1 \mathrm{~s}$ puff of $100 \mu \mathrm{M}$ DHPG in a preloaded MLI in control conditions (first panel), and at different times after the

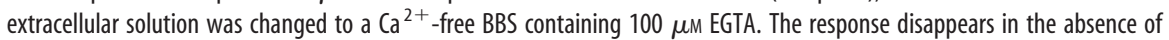
extracellular $\mathrm{Ca}^{2+}$ and recovers when $\mathrm{Ca}^{2+}$ is reintroduced (last panel). $\mathbf{A} \mathbf{2}$ and $\mathbf{A} \mathbf{3}$ show the time course for the signals analyzed in the soma and in a dendritic ROl in the control period (black traces), 4.5 min after $\mathrm{Ca}^{2+}$ removal (red traces), and 9 min after $\mathrm{Ca}^{2+}$ readmission (blue traces). $B$, Pooled data on the effects of $\mathrm{Ca}^{2+}$ removal $\left(n=4 ; \mathrm{Ca}^{2+}\right.$ was removed $4-5$ min before the test puff), U73122 ( $n=5$ with 5 min treatment at $2 \mu \mathrm{M}$ ), and 2-APB ( $n=7$ with 5-7 min treatment at $90 \mu \mathrm{m}$ ). The $y$-axis denotes the ratio between the peak $\Delta F / F_{0}$ responses to $1 \mathrm{~s}$ puffs of DHPG in the test condition over the value obtained in control for the same MLI. * indicates groups in which $p$ was $\leq 0.05$ using the paired Student's $t$ test.

\section{What is the source of $\mathrm{Ca}^{2+}$ during the} mGluR-mediated responses?

To determine the source of $\mathrm{Ca}^{2+}$ during mGluR-mediated responses, we tested various pharmacological and ionic conditions on MLIs preloaded with $\mathrm{Ca}^{2+}$ indicator. Responses were initiated by puff application of quisqualate. We found that $\mathrm{Ca}^{2+}$ removal from the bath for a few minutes eliminated the $\mathrm{Ca}^{2+}$ transients in a reversible manner (Fig. $6 \mathrm{~A}$ ) and that preincubation with 2-APB (90 $\mu \mathrm{M})$, a nonspecific potent blocker of TRPC3, TRPC4, TRPC5, and TRPC6 (van Rossum et al., 2000; Xu et al., 2005), strongly inhibited the response (Fig. $6 \mathrm{~B}$, summary). However, preincubation with U73122, an inhibitor of phospholipase C (PLC), did not affect the initial $\mathrm{Ca}^{2+}$ rise (Fig. $6 \mathrm{~B}$ ). Note that $\mathrm{Ca}^{2+}$ removal abolishes the response in both soma and dendrites (Fig. 6A2, A3), as expected from the similarity of the responses in these two regions (Fig. 4). We conclude from these results that the source of $\mathrm{Ca}^{2+}$ during the first phase of the response is extracellular, and that PLC activation is unnecessary. The effects of 2-APB suggest that the current associated with $\mathrm{mGluR}$ activation is responsible for $\mathrm{Ca}^{2+}$ entry. The receptor responsible for these responses is mGluR1, since CPCCOEt eliminated the agonist-evoked $\mathrm{Ca}^{2+}$ rises ( $n=3$; data not shown).

A very different set of results was found when investigating the $\mathrm{Ca}^{2+}$ response during prolonged quisqualate application. As in the case of the $\mathrm{Ca}^{2+}$ responses to puff application of mGluR agonists described above, prolonged bath application of agonist was only efficient in initiating a $\mathrm{Ca}^{2+}$ response if $\mathrm{Ca}^{2+}$ was present in the bath (Fig. 7A; summary in Fig. 7D). However, once the quisqualate-induced response was initiated, removal of $\mathrm{Ca}^{2+}$ did not prevent the generation of subsequent $\mathrm{Ca}^{2+}$ oscillations (Fig. $7 B$ ). Indeed, $\mathrm{Ca}^{2+}$ removal affected neither the amplitude nor the frequency of ongoing oscillations (Fig. $7 D$, summary). However, on $\mathrm{Ca}^{2+}$ readmission, the cell often went to a high $\mathrm{Ca}^{2+}$ plateau (Fig. $7 B$ ). To estimate the speed of $\mathrm{Ca}^{2+}$ removal from the extracellular space in these experiments, we stimulated the cells extracellularly to elicit action potential-induced $\mathrm{Ca}^{2+}$ rises. We found that these responses were totally eliminated after response (Fig. 7D, summary).

$<2$ min of $\mathrm{Ca}^{2+}$ removal (Fig. 7C). This result clearly demonstrates that the lack of effect of $\mathrm{Ca}^{2+}$ removal is not caused by $\mathrm{Ca}^{2+}$ remaining in the extracellular domain because of diffusion delays.

Because high-threshold L-type $\mathrm{Ca}^{2+}$ channels were previously shown to contribute to somatodendritic $\mathrm{Ca}^{2+}$ rises in MLIs (Chavas et al., 2004), we next asked whether the depolarization that is associated with the activation of the mGluRmediated currents is sufficient to activate these channels, which could then contribute to the resulting $\mathrm{Ca}^{2+}$ signal. We found that addition of the L-type $\mathrm{Ca}^{2+}$ channel blocker nimodipine had effects similar to those of $\mathrm{Ca}^{2+}$ removal from the extracellular media. Whereas nimodipine $(20 \mu \mathrm{M})$ applied before addition of the agonist resulted in a very strong inhibition of the entire response, nimodipine application after the initial agonist induced $\mathrm{Ca}^{2+}$ transient but, during an ongoing oscillation, only resulted in a modest inhibition of the amplitude of each $\mathrm{Ca}^{2+}$ wave, without disrupting the overall pattern of the

The above results indicate that the previously noted differences between the first and subsequent $\mathrm{Ca}^{2+}$ transients correspond to profound differences concerning generation mechanism for each class of transients. Whereas the first transient depends on $\mathrm{Ca}^{2+}$ influx and is amplified by depolarization-induced activation of L-type $\mathrm{Ca}^{2+}$ channels, subsequent transients do not require extracellular $\mathrm{Ca}^{2+}$ or activation of L-type $\mathrm{Ca}^{2+}$ channels. Therefore, the first transient must be generated by $\mathrm{Ca}^{2+}$ entry, but the subsequent transients reflect primarily release from intracellular stores. Finally, it is important to note that the entire $\mathrm{Ca}^{2+}$ oscillatory response is abolished if the generation of the first transient has been prevented by previous $\mathrm{Ca}^{2+}$ removal. Thus, the first transient provides a signal that is necessary for the generation of subsequent oscillations.

\section{Involvement of intracellular $\mathrm{Ca}^{2+}$ stores during prolonged mGluR activation}

mGluR1 receptors are classically coupled to PLC, and activation of this lipase is essential for production of $\mathrm{InsP}_{3}$ in many systems. In cerebellar MLIs, the existence of $\mathrm{InsP}_{3}$-sensitive $\mathrm{Ca}^{2+}$ stores was recently demonstrated (Rengifo et al., 2007). As detailed above, the $\mathrm{Ca}^{2+}$ responses to puff application of quisqualate did not depend on PLC activation (Fig. 6). However, in view of the lack of effect of $\mathrm{Ca}^{2+}$ removal on ongoing oscillations, we asked whether PLC activation could be involved in the recruitment of intracellular $\mathrm{Ca}^{2+}$ stores after the initial response, during the subsequent $\mathrm{Ca}^{2+}$ transients. We therefore compared, in experiments using preloaded cells, the responses to prolonged applications of quisqualate before and after $10 \mathrm{~min}$ exposure to the PLC blocker U73122. On average, there was no change in the oscillation frequency in the presence of the inhibitor (Fig. $8 \mathrm{~A}$ ). Analysis of the areas under the first and subsequent phases of the oscillations shows that the first transient is unaffected, whereas the amplitude of subsequent transients is significantly diminished (Fig. $8 \mathrm{~A}$ ). Control experiments in which two applications of quisqualate were performed at $10 \mathrm{~min}$ intervals in MLIs maintained in 
control saline showed that neither the area nor the frequency of the oscillations changed during the $10 \mathrm{~min}$ period (data not shown; $n=5$ ). These results suggest that PLC-mediated $\mathrm{InsP}_{3}$ production contributes to the maintenance of the $\mathrm{Ca}^{2+}$ oscillations.

To further test the involvement of Ins $\mathrm{P}_{3} \mathrm{Rs}$, responses to quisqualate were analyzed before and after the addition of caffeine $(10 \mathrm{~mm})$ to the bath. At this concentration, caffeine will inhibit $\mathrm{InsP}_{3} \mathrm{Rs}$ and can also activate ryanodine receptors (RyRs) (Bezprozvanny et al., 1994; Hernández-Cruz et al., 1997; Zucchi and Ronca-Testoni, 1997). We observed caffeine-induced $\mathrm{Ca}^{2+}$ transients, presumably caused by RyR activation, in only 1 of 10 MLIs. This suggests that RyRmediated $\mathrm{Ca}^{2+}$ signals are modest in the somatodendritic compartment of MLIs, even though these receptors are located in MLI axons where they generate spontaneous $\mathrm{Ca}^{2+}$ transients (Llano et al., 2000). In accord with this interpretation, exposure to a dose of ryanodine $(100 \mu \mathrm{M})$ expected to fully block RyRs had a small effect on the oscillations, as shown in Figure $8 B$. Oscillation frequency was the same before and after exposure to ryanodine, although the area under the first transient is decreased by the drug (Fig. $8 \mathrm{C}$ shows pooled results from 6 cells). On the other hand, responses to quisqualate were strongly inhibited by caffeine, an effect that reversed on washout to the drug (Fig. 8D). On average, the peak amplitude, the area under the first transient, and the oscillation frequency were significantly decreased by caffeine (Fig. 8E). These results suggest that release of $\mathrm{Ca}^{2+}$ via RyRs contributes to the magnitude of the first transient, whereas $\operatorname{Ins}_{3} \mathrm{Rs}$ are critical for maintaining the subsequent $\mathrm{Ca}^{2+}$ transients during prolonged administration of mGluR agonist.

\section{Discussion}

\section{Cellular mechanisms underlying mGluR1-induced bursting}

Our results show that the firing pattern of MLIs changes dramatically from silence or irregular occasional firing in control conditions to highly regular periodic bursting on activation of mGluR1s. Furthermore, our analysis suggests that in the presence of mGluR1 agonists, periods of spiking are locked to changes in $\mathrm{Ca}^{2+}$. Thus, it is the slow $\mathrm{Ca}^{2+}$ oscillations, with a period of $\sim 30$ $s$, that entrain the bursts of action potentials. Finally, the present results indicate that the first $\mathrm{Ca}^{2+}$ transient has distinctive properties and that this early transient plays an essential functional role in initiating the overall $\mathrm{Ca}^{2+}$ oscillation.

During the initial phase of the response, two synergistic pathways for $\mathrm{Ca}^{2+}$ influx, L-type $\mathrm{Ca}^{2+}$ channels and TRPC-like channels, are engaged by the activation of mGluR1. In preloaded conditions, in which the membrane potential of MLIs can change as a function of the activity of various conductances, the depolarization caused by the cationic current flowing through TRPC-like channels is likely to provide the gating for L-type $\mathrm{Ca}^{2+}$ channels. The $\mathrm{Ca}^{2+}$ influx through these two plasma membrane proteins would sensitize the PLC and the intracellular $\mathrm{Ca}^{2+}$ release channels, creating optimal conditions for an oscillating $\mathrm{Ca}^{2+}$ signal. L-type $\mathrm{Ca}^{2+}$ channels participate in $\mathrm{Ca}^{2+}$ rises elicited in hippocampal CA3 neurons by mossy fiber stimulation, thought to involve group I mGluRs and $\mathrm{InsP}_{3}$-dependent $\mathrm{Ca}^{2+}$ release (Kapur et al., 2001).

Concerning TRPCs, our results add to the growing list of cellular processes in which these proteins participate (for review, see Moran et al., 2004; Owsianik et al., 2006; Gerber et al., 2007). It has been reported that antibodies for TRPC6, but no other types of TRPCs, stain cells in the molecular layer that could be MLIs (Huang et al., 2007). However, immunostaining by Hartmann et al. (2008) shows TRPC3-positive cell bodies in the molecular layer. The properties we obtain for the DHPG-induced currents in MLIs (single-channel conductance of $16 \mathrm{pS}$; current-voltage relation with strong outward rectification) argue for a TRPC3like conductance. However, the lack of pharmacological tools prevents us from dissecting the contribution of specific TRPCs to our responses.

Subsequent $\mathrm{Ca}^{2+}$ oscillations do not require action potentials (Fig. 4) or $\mathrm{Ca}^{2+}$ influx (Fig. 7), but they depend on the activation 

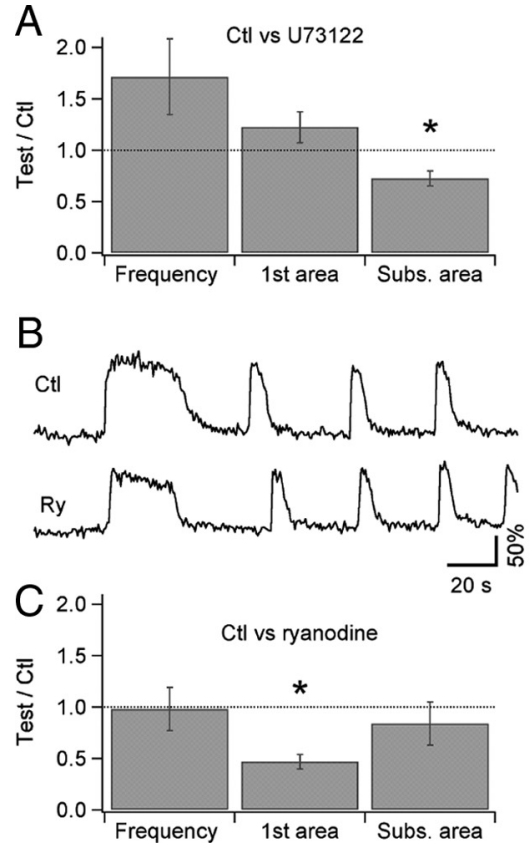
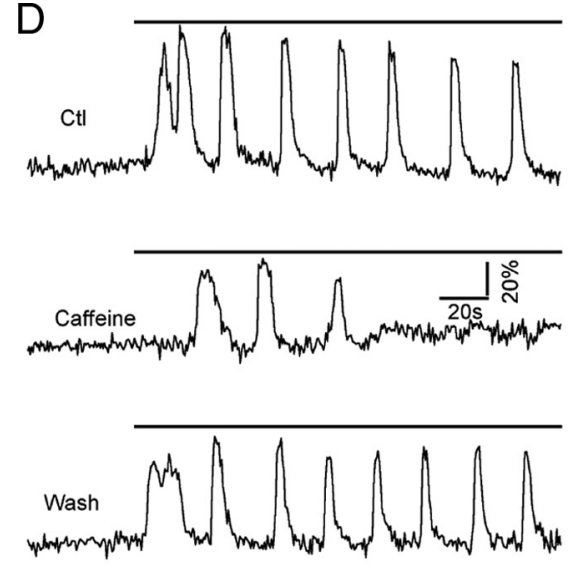

E

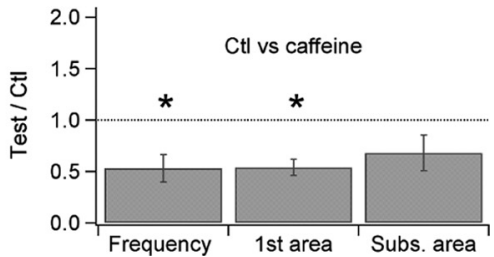

Figure 8. Pharmacological manipulation of $\mathrm{InsP}_{3}$ and ryanodine receptor signaling disturbs the $\mathrm{Ca}^{2+}$ oscillations. $\boldsymbol{A}$, Pooled data $(n=4)$ for the effect of the phospholipase C inhibitor U73122 on quisqualate-evoked C ${ }^{2+}$ oscillations in preloaded MLIs. For each MLI, the responses to bath-applied $2 \mu \mathrm{m}$ quisqualate were analyzed in the control condition and $10 \mathrm{~min}$ after adding U73122 $(2 \mu \mathrm{M})$ to the bath perfusion solution. The treatment did not significantly affect the oscillation frequency or the area under the first $\mathrm{Ca}^{2+}$ transient (first area), but it decreased the area under the subsequent oscillations (Subs. area). B, Oscillatory $\mathrm{Ca}^{2+}$ signals in a preloaded MLI in control condition (top) and $10 \mathrm{~min}$ after addition of $100 \mu \mathrm{m}$ ryanodine to the bath perfusion solution (bottom). $C$, Pooled data $(n=6)$ for the effects of ryanodine on quisqualate-evoked $\mathrm{Ca}^{2+}$ oscillations in preloaded MLIs. For each MLI, the responses to bath-applied $2 \mu \mathrm{m}$ quisqualate were analyzed in the control condition and 10-12 min after ryanodine treatment. Block of RyRs did not affect the oscillation frequency, but it significantly decreased the area under the first transient. $D, 0$ scillatory $\mathrm{Ca}^{2+}$ signals in a preloaded MLI in the control condition (top), 5 min after addition of $10 \mathrm{~mm}$ caffeine to the bath perfusion solution (middle), and 10 min after washing out the caffeine (bottom). $\boldsymbol{E}$, Pooled data $(n=10)$ for the effects of caffeine on quisqualateevoked $\mathrm{Ca}^{2+}$ oscillations in preloaded MLIs. For each MLI, the responses to bath-applied $2 \mu \mathrm{m}$ quisqualate were analyzed in the control condition and 4-5 min after caffeine treatment. Caffeine drastically reduced the oscillation frequency as well as the amplitude of the response, as indicated by the decrease in areas for both the first transient (first area) and the subsequent oscillations (Subs. area). In $\boldsymbol{A}, \boldsymbol{C}$, and $\boldsymbol{E}$, oscillation parameters are expressed as the ratio between the value in the test condition over the value obtained in control saline for the same MLI. * indicates groups in which $p$ was $\leq 0.05$ using the paired Student's $t$ test.

of InsP ${ }_{3}$ Rs (Fig. 8). Thus, the most likely scenario for these transients is a succession of emptying of $\mathrm{Ins}_{3}$-sensitive stores into the cytosol, followed by recapture of cytosolic $\mathrm{Ca}^{2+}$ into the stores. Because blockade of PLC does not abolish the mGluR1-induced response, it appears that the basal $\mathrm{InsP}_{3}$ concentration is sufficient to initiate the response. Nevertheless, blockade of PLC does inhibit the secondary $\mathrm{Ca}^{2+}$ transients, suggesting that activation of mGluR1s and $\mathrm{Ca}^{2+}$ elevation both contribute to activate PLC. Additionally, it is important to note that the continuous presence of agonist is a prerequisite for the generation of the repetitive $\mathrm{Ca}^{2+}$ signals. The reason for such a requirement is likely to be attributable to the fact that $\mathrm{InsP}_{3}$ is continuously degraded in the cytosol, and its speed of degradation increases with cytosolic $\mathrm{Ca}^{2+}$ (Sims and Allbritton, 1998). Therefore, to sustain an $\mathrm{InsP}_{3}-$ dependent oscillation, continuous production of $\mathrm{InsP}_{3}$ is required, and this necessitates continuous binding of agonist by the mGluRs.

A full elucidation of the mechanisms underlying the secondary $\mathrm{Ca}^{2+}$ transients will await further investigation. However, the exact synchrony between firing and the onset of $\mathrm{Ca}^{2+}$ transients during this phase of the response (Fig. 2 B2) suggests that one effect of mGluR1 activation (perhaps via TRPCs) is to allow the start of each transient by depolarizing the cell.

\section{Upstream signaling: potential} stimulation mechanisms

Although the results show that electrical stimulation in the molecular layer can release enough glutamate to trigger mGluR1-induced oscillations, they leave open possibilities of both a PF- and/or a climbing fiber (CF)-mediated stimulation in physiological conditions. In favor of the former possibility, we note that rat cerebellar granule cells (GCs) in vivo spike at high frequency on whisker stimulation (Chadderton et al., 2004). This bursting behavior is well suited to activate mGluRs at PF-MLI synapses. However, the latter option is also attractive for two reasons. First, recent results indicate that CF stimulation activates MLIs by a spillover mechanism, a type of stimulus that preferentially targets mGluRs (Szapiro and Barbour, 2007). Second, work in vivo revealed that MLIs and CFs fire together when animals are subject to tactile (Ekerot and Jörntell, 2001) or to vestibular (Barmack and Yakhnitsa, 2008) stimuli.

As discussed above, the maintenance of oscillations requires continuous binding of agonists by mGluRs. The question then arises as to whether glutamate release on MLIs will ever last sufficiently long to produce oscillatory phenomena. A first glimpse into this issue is provided by GC recordings in nonanesthetized cats in vivo, showing that during cutaneous stimulation, the evoked GC spikes last as long as the stimulus is present (Jörntell and Ekerot, 2006) (these spikes occur at frequencies up to $900 \mathrm{~Hz}$ ). We would then expect that, in a behaving animal subject to continuous tactile stimulation, GCs receiving information from cutaneous inputs will sustain firing for periods of minutes and that such firing will lead to mGluR-mediated oscillatory signals. Determining the exact physiological conditions that may produce $\mathrm{Ca}^{2+}$ oscillations in MLIs will require further investigation.

\section{Downstream signaling: potential functional consequences of $\mathrm{Ca}^{2+}$ waves in MLI bursts}

The PF-stellate synapse displays long-term plasticity involving group I and II postsynaptic mGluRs (Rancillac and Crépel, 2004). The present results suggest that one of the underlying mechanisms for this plasticity is mGluR1-dependent $\mathrm{Ca}^{2+}$ elevation. Furthermore, when mGluR1 activation and subsequent signaling cascades are activated for a sufficiently long period to produce oscillatory signals, profound changes in the mode of firing of MLIs are produced. Such changes could have far-reaching functional consequences. A plausible outcome is a long-term modification in the size of receptive fields, because such a change is induced in vivo by high-frequency trains of PF stimulation applied repeatedly during several minutes (Jörntell and Ekerot, 2002). The possibility that $m$ GluRs are involved in the long-term plasticity of receptive fields has already been discussed by Karakossian and Otis (2004). 
PCs fire bursts of action potentials that are inhibited by the stimulation of complex spikes by CFs (Tank et al., 1988; Cerminara and Rawson, 2004; Womack and Khodakhah, 2004). The present demonstration, that in certain conditions MLIs can similarly adopt a periodic bursting pattern, raises the possibility that in these conditions, MLIs and postsynaptic PCs could oscillate in phase opposition. Because PCs form a recurrent network together with deep cerebellar nuclei and the inferior olive (Llinas et al., 2004), MLI bursting could participate in an overall oscillation pattern involving all of these structures. Such oscillations have already been considered on a much faster time base; here we are pointing out the possibility of a similar scheme with an approximately 1000 times slower period.

\section{Comparison of the effects of mGluR1 activation in interneurons and in principal cells}

In hippocampal CA1 pyramidal neurons, local application of mGluR agonists (Jaffe and Brown, 1994) and synaptic activation of mGluRs (Nakamura et al., 1999) lead to $\mathrm{Ca}^{2+}$ rises that propagate throughout the dendritic arbor and can reach the neuronal soma (Nakamura et al., 1999). In contrast, interneurons exhibit oscillations both of electrical activity (McBain et al., 1994) and $\mathrm{Ca}^{2+}$ levels (Woodhall et al., 1999). The demonstration of robust oscillating signals implicating spike bursts and $\mathrm{Ca}^{2+}$ rises in MLIs raises the possibility of a specific propensity of interneurons to generate slow oscillations in response to mGluR1 activation.

Abnormal motor behavior has been reported in mGluR1 knock-out mice (Aiba et al., 1994; Conquet et al., 1994). Also, mGluR1 is important for synapse elimination during development (Ichise et al., 2000). To date, most of the work on the underlying mechanisms concerns metabotropic signaling in PCs, where group I mGluRs have been extensively studied (for review, see Hartmann and Konnerth, 2009). Activation of PC mGluRs induces slow synaptic potentials, initially described by Batchelor and Garthwaite (1993), for which several molecular substrates have been considered, including $\mathrm{Ca}^{2+}$-permeable smallconductance channels (Canepari et al., 2004) and TRPCs (type C1, Kim et al., 2003; type C3, Hartmann et al., 2008). Additionally, PCs respond to PF stimulation with mGluR-mediated $\mathrm{Ca}^{2+}$ rises engaging $\mathrm{PLC}$-dependent $\mathrm{Ins}_{3}$ production and subsequent $\mathrm{Ca}^{2+}$ release from intracellular stores (Finch and Augustine, 1998; Takechi et al., 1998). In juvenile PCs, mGluRs are also activated on stimulation of CFs, and the ensuing responses play a key role in the pruning of multiple CFs (Dzubay and Otis, 2002). It is presently unclear to which extent the phenotype associated with mGluR1 deficit should be ascribed to MLIs. A major difference between PCs and MLIs concerns the role of PLC, which is directly responsible for the $\mathrm{Ca}^{2+}$ elevation in the former case, but has only a marginal role in the latter case. In addition, whereas Ins $\mathrm{P}_{3}$-linked $\mathrm{Ca}^{2+}$ rises in PCs are restricted to small areas of the dendritic arbor (Finch and Augustine, 1998; Takechi et al., 1998), the responses to mGluR activation that we report for MLIs concern the somatodendritic domain.

In summary, we show that sustained mGluR1 activation leads to a dramatic switch in the spike pattern and $\mathrm{Ca}^{2+}$ oscillations in MLIs. The mechanistic explanation of these changes is explored and roles for both plasma membrane and intracellular channels are described. The slow, highly regular oscillations revealed by the present work are likely to drive pauses in postsynaptic PCs, and could play a role in coordinating slow oscillations involving the cerebello-olivar circuit loop.

\section{References}

Aiba A, Kano M, Chen C, Stanton ME, Fox GD, Herrup K, Zwingman TA, Tonegawa S (1994) Deficient cerebellar long-term depression and impaired motor learning in mGluR1 mutant mice. Cell 79:377-388.

Barbour B, Häusser M (1997) Intersynaptic diffusion of neurotransmitter. Trends Neurosci 20:377-384.

Barmack NH, Yakhnitsa V (2008) Functions of interneurons in mouse cerebellum. J Neurosci 28:1140-1152.

Batchelor AM, Garthwaite J (1993) Novel synaptic potentials in cerebellar Purkinje cells: probable mediation by metabotropic glutamate receptors. Neuropharmacology 32:11-20.

Baude A, Nusser Z, Roberts JD, Mulvihill E, McIlhinney RA, Somogyi P (1993) The metabotropic glutamate receptor (mGluR1 alpha) is concentrated at perisynaptic membrane of neuronal subpopulations as detected by immunogold reaction. Neuron 11:771-787.

Bengtson CP, Tozzi A, Bernardi G, Mercuri NB (2004) Transient receptor potential-like channels mediate metabotropic glutamate receptor EPSCs in rat dopamine neurones. J Physiol 555:323-330.

Berg AP, Sen N, Bayliss DA (2007) TrpC3/C7 and Slo2.1 are molecular targets for metabotropic glutamate receptor signaling in rat striatal cholinergic interneurons. J Neurosci 27:8845-8856.

Bezprozvanny I, Bezprozvannaya S, Ehrlich BE (1994) Caffeine-induced inhibition of inositol(1,4,5)-trisphosphate-gated calcium channels from cerebellum. Mol Biol Cell 5:97-103.

Canepari M, Auger C, Ogden D (2004) $\mathrm{Ca}^{2+}$ ion permeability and singlechannel properties of the metabotropic slow EPSC of rat Purkinje neurons. J Neurosci 24:3563-3573.

Carter AG, Regehr WG (2000) Prolonged synaptic currents and glutamate spillover at the parallel fiber to stellate cell synapse. J Neurosci 20:4423-4434.

Cerminara NL, Rawson JA (2004) Evidence that climbing fibers control an intrinsic spike generator in cerebellar Purkinje cells. J Neurosci 24:4510-4517.

Chadderton P, Margrie TW, Häusser M (2004) Integration of quanta in cerebellar granule cells during sensory processing. Nature 428:856-860.

Chavas J, Forero ME, Collin T, Llano I, Marty A (2004) Osmotic tension as a possible link between $\mathrm{GABA}(\mathrm{A})$ receptor activation and intracellular calcium elevation. Neuron 44:701-713.

Clapham, DE (2009) Clapham Lab Publications, http://clapham.tch. harvard.edu.

Collin T, Chat M, Lucas MG, Moreno H, Racay P, Schwaller B, Marty A, Llano I (2005) Developmental changes in parvalbumin regulate presynaptic $\mathrm{Ca}^{2+}$ signaling. J Neurosci 25:96-107.

Conquet F, Bashir ZI, Davies CH, Daniel H, Ferraguti F, Bordi F, Franz-Bacon K, Reggiani A, Matarese V, Condé F, Collingridge GL, Crépel F (1994) Motor deficit and impairment of synaptic plasticity in mice lacking mGluR1. Nature 372:237-243.

Conti R, Tan YP, Llano I (2004) Action potential-evoked and ryanodinesensitive spontaneous $\mathrm{Ca}^{2+}$ transients at the presynaptic terminal of a developing CNS inhibitory synapse. J Neurosci 24:6946-6957.

Dietrich A, Mederos y Schnitzler M, Emmel J, Kalwa H, Hofmann T, Gudermann T (2003) N-linked protein glycosylation is a major determinant for basal TRPC3 and TRPC6 channel activity. J Biol Chem 278:47842-47852.

Dzubay JA, Otis TS (2002) Climbing fiber activation of metabotropic glutamate receptors on cerebellar Purkinje neurons. Neuron 36:1159-1167.

Ekerot CF, Jörntell H (2001) Parallel fibre receptive fields of Purkinje cells and interneurons are climbing fibre-specific. Eur J Neurosci 13:1303-1310.

Ene FA, Kalmbach A, Kandler K (2007) Metabotropic glutamate receptors in the lateral superior olive activate TRP-like channels: age- and experience-dependent regulation. J Neurophysiol 97:3365-3375.

Finch EA, Augustine GJ (1998) Local calcium signaling by inositiol-1,4,5trisphosphate in Purkinje cell dendrites. Nature 396:753-756.

Fukunaga I, Yeo CH, Batchelor AM (2007) The mGlul antagonist CPCCOEt enhances the climbing fibre response in Purkinje neurones independently of glutamate receptors. Neuropharmacology 52:450-458.

Gee CE, Benquet P, Gerber U (2003) Group I metabotropic glutamate receptors activate a calcium-sensitive transient receptor potential-like conductance in rat hippocampus. J Physiol 546:655-664.

Gerber U, Gee CE, Benquet P (2007) Metabotropic glutamate receptors: intracellular signaling pathways. Curr Opin Pharmacol 7:56-61. 
Hartmann J, Konnerth A (2009) Mechanisms of metabotropic glutamate receptor-mediated synaptic signaling in cerebellar Purkinje cells. Acta Physiol 195:79-90.

Hartmann J, Dragicevic E, Adelsberger H, Henning HA, Sumser M, Abramowitz J, Blum R, Dietrich A, Freichel M, Flockerzi V, Birnbaumer L, Konnerth A (2008) TRPC3 channels are required for synaptic transmission and motor coordination. Neuron 59:392-398.

Häusser M, Clark BA (1997) Tonic synaptic inhibition modulates neuronal output pattern and spatiotemporal synaptic integration. Neuron 19:665-678.

Hernández-Cruz A, Escobar AL, Jiménez N (1997) $\mathrm{Ca}^{2+}$-induced $\mathrm{Ca}^{2+}$ release phenomena in mammalian sympathetic neurons are critically dependent on the rate of rise of trigger $\mathrm{Ca}^{2+}$. J Gen Physiol 109:147-167.

Huang WC, Young JS, Glitsch MD (2007) Changes in TRPC channel expression during postnatal development of cerebellar neurons. Cell Calcium 42:1-10.

Ichise T, Kano M, Hashimoto K, Yanagihara D, Nakao K, Shigemoto R, Katsuki M, Aiba A (2000) mGluR1 in cerebellar Purkinje cells essential for long-term depression, synapse elimination, and motor coordination. Science 288:1832-1835.

Jaffe DB, Brown TH (1994) Metabotropic glutamate receptor activation induces calcium waves within hippocampal dendrites. J Neurophysiol 72:471-474.

Jörntell H, Ekerot CF (2002) Reciprocal bidirectional plasticity of parallel fibre receptive fields in cerebellar Purkinje cells and their afferent interneurons. Neuron 34:797-806.

Jörntell H, Ekerot CF (2006) Properties of somatosensory integration in cerebellar granule cells in vivo. J Neurosci 26:11786-11797.

Kamouchi M, Philipp S, Flockerzi V, Wissenbach U, Mamin A, Raeymaekers L, Eggermont J, Droogmans G, Nilius B (1999) Properties of heterologously expressed hTRP3 channels in bovine pulmonary artery endothelial cells. J Physiol 518:345-358.

Kapur A, Yeckel M, Johnston D (2001) Hippocampal mossy fiber activity evokes $\mathrm{Ca}^{2+}$ release in CA3 pyramidal neurons via a metabotropic glutamate receptor pathway. Neuroscience 107:59-69.

Karakossian MH, Otis TS (2004) Excitation of cerebellar interneurones by group I metabotropic glutamate receptors. J Neurophysiol 92:1558-1565.

Kawabata S, Tsutsumi R, Kohara A, Yamaguchi T, Nakanishi S, Okada M (1996) Control of calcium oscillations by phosphorylation of metabotropic glutamate receptors. Nature 383:89-92.

Kawabata S, Kohara A, Tsutsumi R, Itahana H, Hayashibe S, Yamaguchi T, Okada M (1998) Diversity of calcium signaling by metabotropic glutamate receptors. J Biol Chem 273:17381-17385.

Kim SJ, Kim YS, Yuan JP, Petralia RS, Worley PF, Linden DJ (2003) Activation of the TRPC1 cation channel by metabotropic glutamate receptor mGluR1. Nature 426:285-291.

Kondo S, Marty A (1998) Synaptic currents at individual connections among stellate cells in rat cerebellar slices. J Physiol 509:221-232.

Llano I, Marty A (1995) Presynaptic metabotropic glutamate regulation of inhibitory synapses in rat cerebellar slices. J Physiol 486:163-176.

Llano I, González J, Caputo C, Lai AF, Blayney LM, Tan YP, Marty A (2000) Ryanodine-sensitive $\mathrm{Ca}^{2+}$ stores underlie large amplitude miniature IPSCs and spontaneous presynaptic $\mathrm{Ca}^{2+}$ transients at Purkinje cell synapses. Nat Neurosci 3:1256-1265.

Llinas RR, Walton KD, Lang EJ (2004) Cerebellum. In: The synaptic organization of the brain (Shepherd GM, ed), pp. 271-309. New York: Oxford UP.

Mann-Metzer P, Yarom Y (1999) Electrotonic coupling interacts with intrinsic properties to generate synchronized activity in cerebellar networks of inhibitory interneurons. J Neurosci 19:3298-3306.

McBain CJ, Fisahn A (2001) Interneurons unbound. Nat Rev Neurosci 2:11-23.

McBain CJ, DiChiara TJ, Kauer JA (1994) Activation of metabotropic glutamate receptors differentially affects two classes of hippocampal interneurons and potentiates excitatory synaptic transmission. J Neurosci 14:4433-4445.

Moran MM, Xu H, Clapham DE (2004) TRP ion channels in the nervous system. Curr Opin Neurobiol 14:362-369.

Moroni F, Lombardi G, Thomsen C, Leonardi P, Attucci S, Peruginelli F, Torregrossa SA, Pellegrini-Giampietro DE, Luneia R, Pellicciari R (1997)
Pharmacological characterization of 1-aminoindan-1,5-dicarboxylic acid, a potent mGluR1 antagonist. J Pharmacol Exp Ther 281:721-729.

Nakamura T, Barbara JG, Nakamura K, Ross WN (1999) Synergistic release of $\mathrm{Ca}^{2+}$ from $\mathrm{IP}_{3}$-sensitive stores evoked by synaptic activation of mGluRs paired with backpropagating action potentials. Neuron 24:727-737.

Otani S, Auclair N, Desce JM, Roisin MP, Crépel F (1999) Dopamine receptors and groups I and II mGluRs cooperate for long-term depression induction in rat prefrontal cortex through converging postsynaptic activation of MAP kinases. J Neurosci 19:9788-97802.

Owsianik G, Talavera K, Voets T, Nilius B (2006) Permeation and selectivity of TRP channels. Annu Rev Physiol 68:685-717.

Pedersen SF, Owsianik G, Nilius B (2005) TRP channels: an overview. Cell Calcium 38:233-252.

Ramsey IS, Delling M, Clapham DE (2006) An introduction to TRP channels. Annu Rev Physiol 68:619-647.

Rancillac A, Crépel F (2004) Synapses between parallel fibres and stellate cells express long-term changes in synaptic efficacy in rat cerebellum. J Physiol 554:707-720.

Rengifo J, Gibson CJ, Winkler E, Collin T, Ehrlich BE (2007) Regulation of the inositol 1,4,5-trisphosphate receptor type I by $O$-GlcNAc glycosylation. J Neurosci 27:13813-13821.

Rossi B, Maton G, Collin T (2008) Calcium-permeable presynaptic AMPA receptors in cerebellar molecular layer interneurones. J Physiol 586:5129-5145.

Shin JH, Kim YS, Worley PF, Linden DJ (2009) Depolarization induced slow current in cerebellar Purkinje cells does not require mGluR1. Neuroscience. Advance online publication. Retrieved June 18, 2009. doi:10.1016/j.neuroscience.2009.01.044.

Sims CE, Allbritton NL (1998) Metabolism of inositol 1,4,5-trisphosphate and inositol 1,3,4,5-tetrakisphosphate by the oocytes of Xenopus laevis. J Biol Chem 13:4052-4058.

Strübing C, Krapivinsky G, Krapivinsky L, Clapham DE (2001) TRPC1 and TRPC5 form a novel cation channel in mammalian brain. Neuron 29:645-655.

Szapiro G, Barbour B (2007) Multiple climbing fibers signal to molecular layer interneurons exclusively via glutamate spillover. Nat Neurosci 10:735-742.

Takechi H, Eilers J, Konnerth A (1998) A new class of synaptic response involving calcium release in dendritic spines. Nature 396:757-760.

Tan YP, Llano I, Hopt A, Würriehausen F, Neher E (1999) Fast scanning and efficient photodetection in a simple two-photon microscope. J Neurosci Methods 92:123-135.

Tank DW, Sugimori M, Connor JA, Llinás RR (1988) Spatially resolved calcium dynamics of mammalian Purkinje cells in cerebellar slice. Science 242:773-777.

Vaca L, Sampieri A (2002) Calmodulin modulates the delay period between release of calcium from internal stores and activation of calcium influx via endogenous TRP1 channels. J Biol Chem 277:42178-42187.

van Rossum DB, Patterson RL, Ma HT, Gill DL (2000) $\mathrm{Ca}^{2+}$ entry mediated by store depletion, $S$-nitrosylation, and TRP3 channels. Comparison of coupling and function. J Biol Chem 275:28562-28568.

Vincent P, Marty A (1996) Fluctuations of inhibitory post-synaptic currents in Purkinje cells from rat cerebellar slices. J Physiol 494:183-199.

Walker RL, Koh SD, Sergeant GP, Sanders KM, Horowitz B (2002) TRPC4 currents have properties similar to the pacemaker current in interstitial cells of Cajal. Am J Physiol Cell Physiol 283:C1637-C1645.

Wang M, Bianchi R, Chuang SC, Zhao W, Wong RK (2007) Group I metabotropic glutamate receptor-dependent TRPC channel trafficking in hippocampal neurons. J Neurochem 101:411-421.

Womack MD, Khodakhah K (2004) Dendritic control of spontaneous bursting in cerebellar Purkinje cells. J Neurosci 24:3511-3521.

Woodhall G, Gee CE, Robitaille R, Lacaille JC (1999) Membrane potential and intracellular $\mathrm{Ca}^{2+}$ oscillations activated by mGluRs in hippocampal stratum oriens/alveus interneurons. J Neurophysiol 81:371-382.

Xu SZ, Zeng F, Boulay G, Grimm C, Harteneck C, Beech DJ (2005) Block of TRPC5 channels by 2-aminoethoxydiphenyl borate: a differential, extracellular and voltage-dependent effect. Br J Pharmacol 145:405-414.

Zucchi R, Ronca-Testoni S (1997) The sarcoplasmic reticulum Ca2 + channel/ryanodine receptor: modulation by endogenous effectors, drugs and disease states. Pharmacol Rev 49:1-51. 